\title{
COMPARISON OF DOPPLER INDICES OF BILATERAL SUPERIOR THYROID ARTERIES IN EUTHYROID AND HYPERTHYROID PATIENTS
}

\author{
Abdul Rasheed Valiyapalathingal ${ }^{1}$, Adarsh K. $M^{2}$ \\ 1 Postgraduate Student, Department of Radiodiagnosis, Yenepoya Medical College, Mangalore, Karnataka, India. \\ ${ }^{2}$ Assistant Professor, Department of Radiodiagnosis, Yenepoya Medical College, Mangalore, Karnataka, India.
}

\section{BACKGROUND}

\section{ABSTRACT}

In this case-control study we aim to establish the relationship between the Doppler indices of the superior thyroid arteries and the functioning of the thyroid gland as seen by the thyroid function tests, ultrasonographic evaluation and colour Doppler of the thyroid gland.

\section{METHODS}

In this case-control study, ultrasonography of the thyroid gland with colour Doppler evaluation with Doppler indices of bilateral superior thyroid arteries and correlation with thyroid function test was done for patients presenting to the radio-diagnosis OPD. The total sample size was calculated using G*Power software with a level of significance alpha $=5 \%$ and power 1 - beta $=80 \%$; the effect size $d=0.75$ with $95 \%$ confidence interval. The minimum sample size required in each group is 48 with a total sample size of 96. The data obtained was analysed with independent samples test.

\section{RESULTS}

Data was analysed using independent samples test with Levene's test for equality of variances and t-test for Equality of Means also done. Of all the patients $(n=96)$ who came for ultrasound scan of thyroid gland, $70 \%(n=67)$ belonged to the $20-50$ age group. 48 patients were included in the cases group, of this $79 \%(n=38)$ were female and $21 \%(n=10)$ were males. We found that the Doppler indices of STA in hyperthyroid patients were significantly higher than euthyroid subjects with $\mathrm{p}$ value $<0.05$. The controls $(n=48)$ had a mean PSV-STA of $15.85 \pm 1.89 \mathrm{~cm} / \mathrm{s}$, mean PI-STA of $0.9 \pm 0.12$ and mean RI-STA of $0.55 \pm 0.07$. The Doppler indices of hyperthyroid patients $(\mathrm{n}=48)$ was elevated with mean PSV-STA $(\mathrm{cm} / \mathrm{s})$ of $37.15 \pm 7.6$, the mean RI-STA of $0.72 \pm 0.1$ and mean PI-STA of $1.79 \pm 0.23$.

\section{CONCLUSIONS}

We found that there was significant correlation between the Doppler indices and the euthyroid or hyperthyroid status of the subject. It was in accordance with the studies reviewed in the review of literature for this study and the expected results were achieved. It may be suggested that the colour Doppler evaluation with assessment of the Doppler indices should be done in all patients who present with suspicion of hyperthyroidism and a TFT result which maybe subclinical or inconclusive. The Doppler indices in such cases may be helpful in diagnosing and categorizing patients with otherwise questionable reports.

HOW TO CITE THIS ARTICLE: Valiyapalathingal AR, Adarsh KM. Comparison of Doppler indices of bilateral superior thyroid arteries in euthyroid and hyperthyroid patients. J. Evolution Med. Dent. Sci. 2019;8(13):1016-1022, DOI: $10.14260 /$ jemds/2019/226

\section{BACKGROUND}

Thyroid function test and ultrasonography are two modalities of thyroid assessment that are easily available and widely used in medical practice today.

Doppler sonography can demonstrate normal thyroid anatomy and pathologic conditions with remarkable clarity. ${ }^{1}$ The homogenous echotexture of the thyroid gland make it easy for detection for any nodular lesions in the gland via high frequency ultrasonography. In ultrasonographic evaluation of the thyroid gland the size of the gland, the echotexture and the intra-glandular vascularity is usually considered to make a radiological diagnosis of thyroiditis.

'Financial or Other Competing Interest': None.

Submission 14-02-2019, Peer Review 18-03-2019,

Acceptance 25-03-2019, Published 01-04-2019.

Corresponding Author:

Dr. Adarsh K. M.

Assistant Professor,

Department of Radio-diagnosis

Yenepoya Medical College,

Deralakatte,

Mangalore-575018,

Karnataka, India.

E-mail: adiarticles@gmail.com

DOI: $10.14260 /$ jemds $/ 2019 / 226$
Even though in patients in hyperthyroid state, thyroid scintigraphy is the gold standard in establishing and differentiating the cause for the same, it is not widely available and not cost effective. Hence, high frequency ultrasonography and colour Doppler are routinely used and easily available in studying the thyroid gland along with thyroid function test.

The Doppler examination of the superior and inferior thyroid arteries are not routinely done in assessment of the thyroid gland. Doppler studies on thyrotoxicosis have found high systolic velocities.[2-5] Limited studies have been done to establish normal Doppler parameters of thyroid arteries.[6,7]

From the perspective of blood vessel detection, it is rather difficult to accurately position while measuring the velocity of inferior thyroid artery. ${ }^{8}$ The ITA is deeply located, ${ }^{9}$ and hence accurate positioning is difficult. By contrast, STA is superficial, and can be easily positioned from its intersecting point with thyroid lobes. In addition, anatomic variation of STA rarely occurs. ${ }^{10}$

The relationship between the Doppler indices of the superior thyroid arteries and the functioning of the thyroid gland as seen by the thyroid function tests, ultrasonographic evaluation and color Doppler of the thyroid gland needs further evaluation. 


\section{Normal Anatomy of The Thyroid}

The gland is brownish red and highly vascular and lies approximately at the level of the $5^{\text {th }}$ cervical to the $1^{\text {st }}$ thoracic vertebra. The gland is ensheathed by the pretracheal layer of deep cervical fascia. Its weight is usually about 25 grams but varies, being slightly heavier in females and enlarging during menstruation and pregnancy. The lobes of the thyroid are approximately conical; their ascending apices diverging laterally to the level of the oblique lines on the lamina of the thyroid cartilages and their bases are level with the fourth or fifth tracheal cartilages.

The isthmus connects each lobe's lower parts. It measures $1.25 \mathrm{~cm}$ transversely and vertically and is usually anterior to the second and third tracheal cartilages. The superior arteries anastomose along its upper border.

At the lower border the inferior thyroid veins leave the gland. Small detached masses of thyroid tissue may occur above the lobes or isthmus as accessory thyroid glands. ${ }^{11}$

\section{Blood Supply of Thyroid Gland 12}

The thyroid gland receives a dual blood supply from the superior and inferior thyroid arteries that have abundant collateral anastomoses with each other from both ipsilateral and contralateral vessels. 11

\section{Superior Thyroid Artery}

This is the first anterior branch of the external carotid artery. In a small percentage of cases it may arise from the common carotid artery just before its bifurcation.

Near the upper pole of the lateral lobe the superior thyroid artery sends a small branch, the cricothyroid artery across the cricothyroid muscle towards the midline. Anastomosis of the vessels is seen with its opposite side in the midline on the surface of the median cricothyroid ligament. 11

\section{Inferior Thyroid Artery}

This artery arises from the thyrocervical trunk, a branch of the first part of the subclavian artery at the level of the first rib. It ascends vertically for a short distance before turning medially, forming an arching loop and entering the tracheoesophageal groove. Most of the small branches penetrate the posterior aspect of the lateral lobe apart from a longitudinal branch that anastomosis with the superior thyroid artery near the superior lobe. ${ }^{11}$

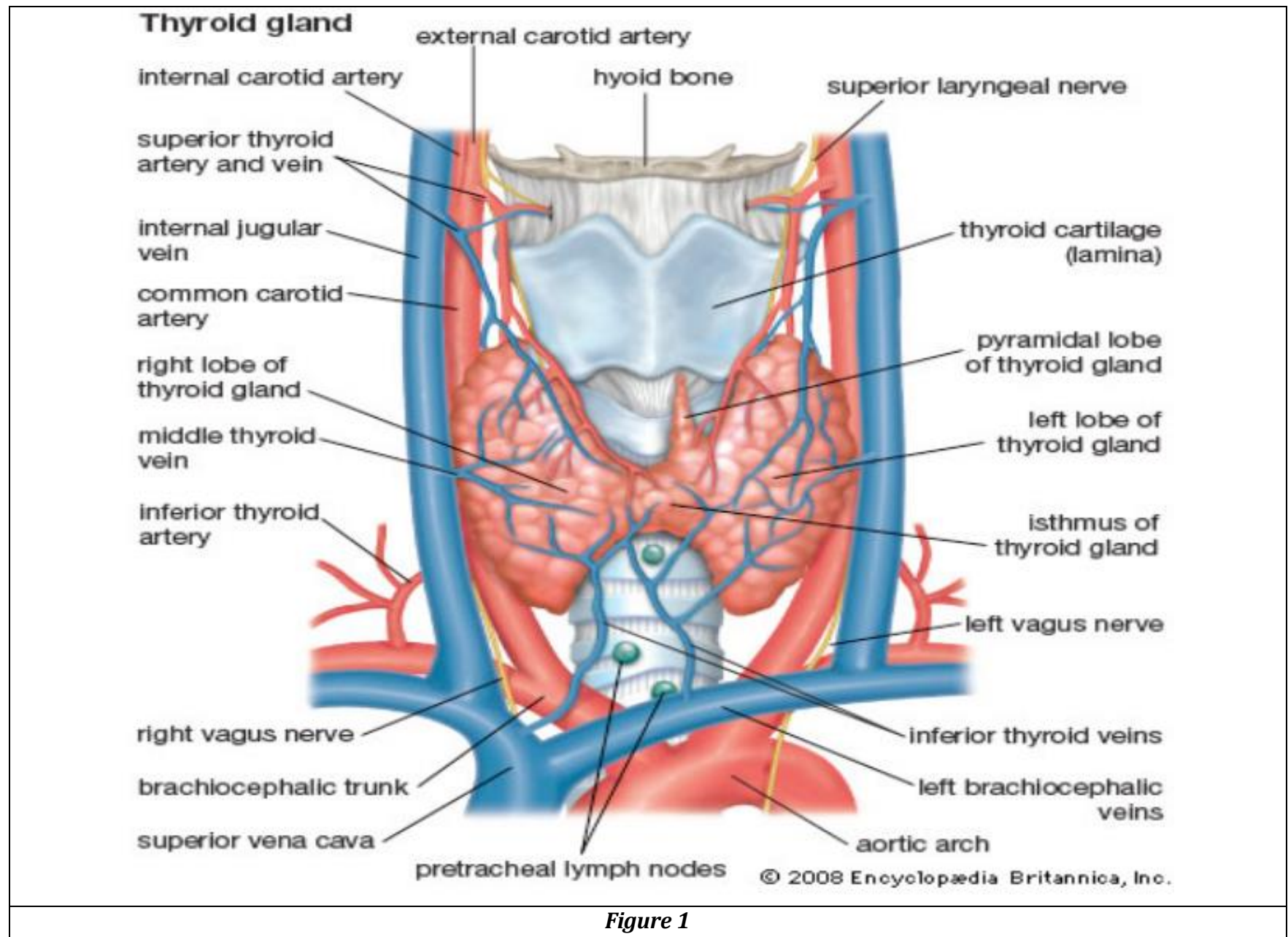

\section{Normal Thyroid in Ultrasonography}

Normal thyroid parenchyma has a homogenous hyperechogenicity, which makes detection of focal cystic or hypoechoic thyroid lesions relatively easy in most cases. The thin hyperechoic line that bonds the thyroid lobes in the capsule is often identifiable by US. When anterior-posterior diameter is more than $2 \mathrm{~cm}$, the thyroid gland may be considered enlarged. 


\section{Thyroiditis}

This disease commonly mimics other thyroid diseases causing both thyrotoxicosis and hypothyroidism. The thyroid may be diffusely enlarged, nodular or non-palpable. Thyroiditis may easily be confused with Grave's disease, multinodular goiter or an autonomously hyperfunctioning nodule. Certain forms of thyroiditis present as asymptomatic nodules and are difficult to distinguish from thyroid carcinoma. Conversely one clinical presentation of papillary thyroid carcinoma with diffuse goiter and antithyroid antibodies may mimic Hashimoto's thyroiditis that it has been termed pseudothyroiditis. ${ }^{13}$

The typical appearance by sonography of an acute infection is enlargement of the gland that might be either focal or diffuse and hypoechogenic due to of oedema. In children a pyriform sinus fistulous communication with the thyroid may result in acute inflammation of the thyroid particularly noticed on the left side. ${ }^{14} \mathrm{~A}$ diffuse sonolucent appearance of the thyroid is highly suggestive of inflammatory disease.

\section{METHODS}

All patients above 18 years of age presenting to the radiodiagnosis OPD of for an ultrasonography of neck, who also have a thyroid function test done, was considered for the study. The thyroid function test results of all patients were analysed and cross-checked against the inclusion criteria for inclusion into the study as either controls or cases.

Patients were taken for ultrasonography and it was done using a linear high frequency (7 - $11 \mathrm{MHz}$ ) ultrasonography probe by the principal investigator who is having more than 2 years' experience with ultrasonography of thyroid gland and who is blinded to the thyroid function test at the time of the scan to avoid bias; and reported.

Initially B-mode scan was done to look for echogenicity of the thyroid gland and also for any focal lesions or nodules.

All patients were categorized into three groups based on ultrasonography report-

1. Having a normal ultrasonography report.

2. Having ultrasonography diffuse thyroid disease without any nodular or focal lesions.

3. Having ultrasonography report causing exclusion from the study.

Doppler indices, namely Peak systolic velocity (PSV), Resistive index (RI) and Pulsatility Index (PI) of bilateral superior thyroid arteries will be measured in patients allotted to category 1 (control) and 2 (cases).

\section{Method of Assessment of Doppler Indices}

With the patient positioned in the same way as for ultrasonography of neck, the patient was asked to turn his head to his left side to assess the right superior thyroid artery.
In axial view, the common carotid artery on the right side is identified as the circular pulsatile vessel and it traced superiorly till its bifurcation. The external carotid artery, which is smaller in caliber and medial in location as compared to the internal carotid artery is focused on and brought to the center of the screen.

The superior thyroid artery is the first branch in the external carotid artery arising anteriorly at the level of the hyoid bone and can be traced up to the upper pole off the gland using colour Doppler mode. Spectral waveforms were taken at a distance of 1-2 cms from the origin of the artery with a sample gate size of $1 \mathrm{~mm}$ and Doppler angle of 30-60.

\section{Study Design}

Case-Control study.

\section{Sample Size (Including Sample Size Calculation)}

Total sample size is calculated using G*Power software. Level of significance alpha $=5 \%$; Power 1 - beta $=80 \%$. Effect size $d$ $=0.75$ with $95 \%$ confidence interval.

The minimum sample size required in each group is 48 . Total sample size is 96 .

\section{Analysis}

Data obtained was analysed using the IBM SPSS statistics software ${ }^{15}$ version 23 ; and independent samples test with Levene's test for equality of variances and t-test for Equality of Means also done.

\section{RESULTS}

The data collected were analysed in terms of demographics such as age and sex. The mean PSV, RI and PI of bilateral superior thyroid arteries of hyperthyroid patients were analysed, and comparison was made with the mean PSV, RI and PI of bilateral superior thyroid arteries of euthyroid patients.

Thyroid diseases are more common in middle aged women; this was in accordance with the data that was collected and studied.

The peak systolic velocities (PSV) and Pulsatility Index (PI) of hyperthyroid patients were significantly increased as compared to euthyroid patients. This was also the expected result as seen in the review of literature done.

The other Doppler indices, such as the Resistive index (RI) and the Pulsatility Index (PI) were also elevated but were not as significant as the peak systolic velocities (PSV).

\begin{tabular}{|c|c|c|}
\hline Age & Cases & Controls \\
\hline $10-20$ & 1 & 4 \\
\hline $21-30$ & 11 & 9 \\
\hline $31-40$ & 17 & 10 \\
\hline $41-50$ & 8 & 12 \\
\hline $51-60$ & 10 & 6 \\
\hline $61-70$ & 1 & 7 \\
\hline \multicolumn{3}{|c|}{ Age Distribution } \\
\hline
\end{tabular}




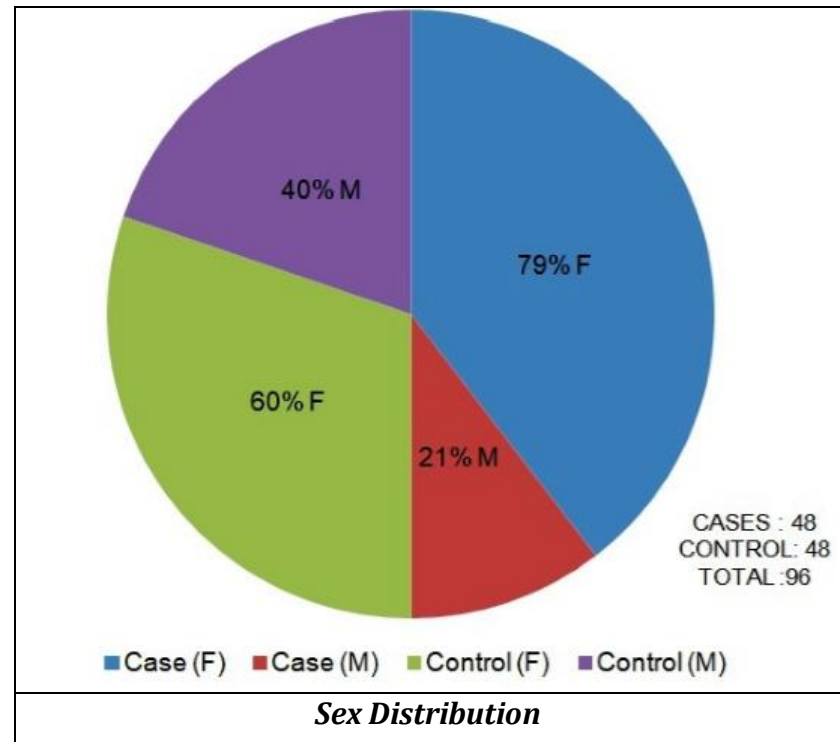

Of all the patients included in the study $(n=96)$ that came for ultrasound scan of thyroid gland, $70 \%(n=67)$ belonged to the 20 -50 age group.

48 patients were included in the cases group based on thyroid function test results and the ultrasonography reports, of this $79 \%(n=38)$ were female and $21 \%(n=10)$ were males.

The control group with 48 patients also had more female patients than males with a 60:40 split.

\section{Doppler Indices (Cases)}
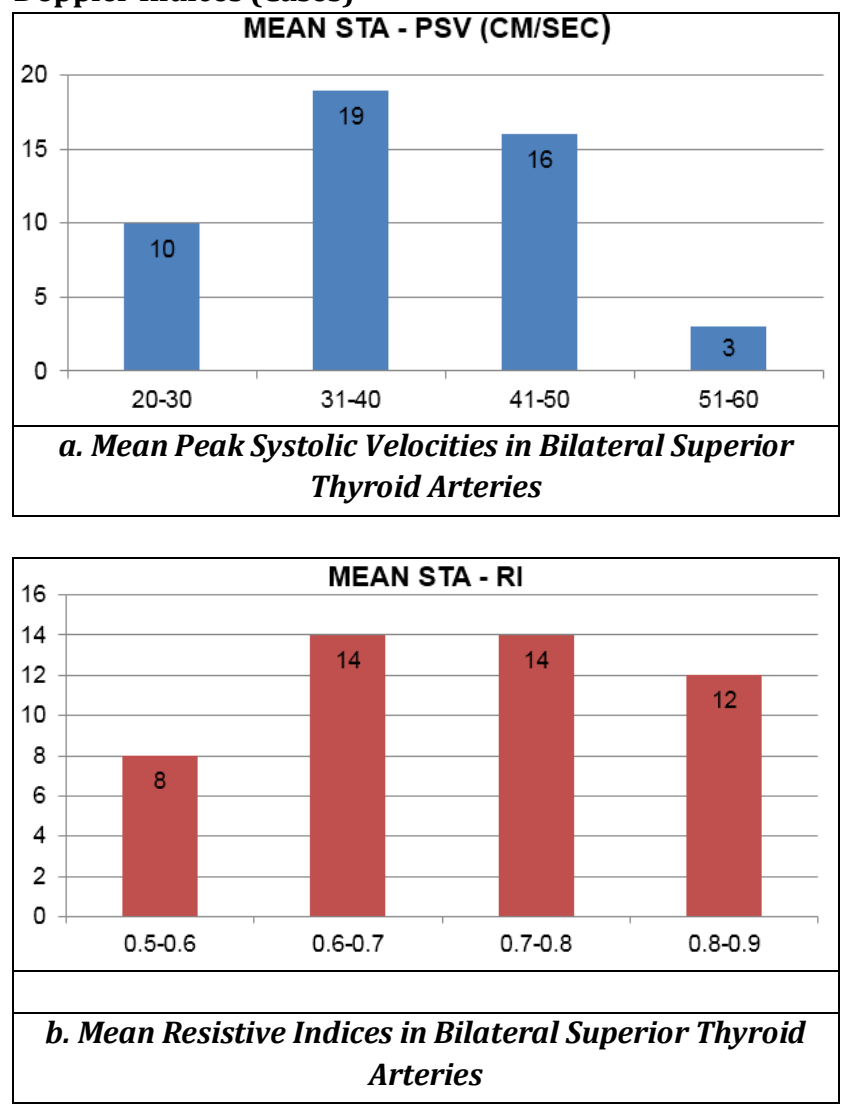

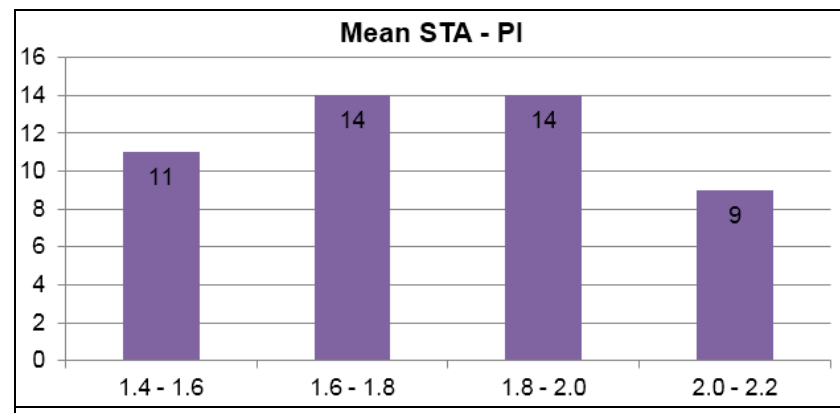

c. Mean Pulsatility Indices in Bilateral Superior Thyroid Arteries

\begin{tabular}{|c|c|c|c|c|c|}
\hline \multicolumn{7}{|c|}{ Group Statistics } \\
\hline & $\begin{array}{c}\text { Grouping } \\
\text { Variable }\end{array}$ & No. & Mean & $\begin{array}{c}\text { Std. } \\
\text { Deviation }\end{array}$ & $\begin{array}{c}\text { Std. } \\
\text { Error } \\
\text { Mean }\end{array}$ \\
\hline Mean & Case & 48 & 37.15 & 7.597 & 1.097 \\
\cline { 2 - 6 } STA-PSV & Control & 48 & 15.86 & 1.897 & 0.274 \\
\hline Mean & Case & 48 & 0.72 & 0.098 & 0.014 \\
\cline { 2 - 6 } STA-RI & Control & 48 & 0.55 & 0.070 & 0.010 \\
\hline Mean & Case & 48 & 1.79 & 0.227 & 0.033 \\
\cline { 2 - 6 } STA-PI & Control & 48 & 0.90 & 0.122 & 0.018 \\
\hline
\end{tabular}

The peak mean systolic velocities in the superior thyroid arteries in euthyroid patients ranged from 12 to $21 \mathrm{~cm} / \mathrm{sec}$, with a mean value of $15.85 \mathrm{~cm} / \mathrm{sec}$.

In the 48 hyperthyroid patients studied in the cases group, the peak mean systolic velocities in the superior thyroid arteries ranged from 23 to $53 \mathrm{~cm} / \mathrm{sec}$ with a mean value of $37.15 \mathrm{~cm} / \mathrm{sec}$.

The resistive indices of the superior thyroid arteries in the euthyroid patients ranged from 0.44 to 0.67 with a mean value of 0.55 ; and in the hyperthyroid patients ranged from 0.55 to 0.88 with a mean value of 0.72 .

The PI in the euthyroid patients ranged from 0.6 to 1.2 , with an average PI of 0.9; while the PI in the hyper thyroid patients ranged from 1.4 to 2.2 with an average PI of 1.79 .

The peak mean systolic velocities and the mean resistive indices of the hyperthyroid patients were significantly elevated compared to the euthyroid patients with $\mathrm{p}$-value being $<0.05$ in both the indices measured.

The mean Pulsatility Indices of the bilateral superior thyroid arteries in the hyperthyroid patients were also significantly higher than the euthyroid patients $(P<0.05)$ with no overlap in the values. 


\begin{tabular}{|c|c|c|c|c|c|c|c|c|c|c|}
\hline & \multicolumn{2}{|c|}{$\begin{array}{l}\text { Levene's Test for } \\
\text { Equality of } \\
\text { Variances }\end{array}$} & \multicolumn{7}{|c|}{ t-Test for Equality of Means } \\
\hline & & \multirow[t]{2}{*}{$\mathbf{F}$} & \multirow[t]{2}{*}{ Sig. } & \multirow[t]{2}{*}{$\mathbf{t}$} & \multirow[t]{2}{*}{ df } & \multirow[t]{2}{*}{$\begin{array}{l}\text { Sig (2- } \\
\text { tailed) } \\
\text { p-value }\end{array}$} & \multirow[t]{2}{*}{$\begin{array}{c}\text { Mean } \\
\text { Difference }\end{array}$} & \multirow[t]{2}{*}{$\begin{array}{l}\text { Std. Error } \\
\text { Difference }\end{array}$} & \multicolumn{2}{|c|}{$\begin{array}{l}\text { 95\% Confidence } \\
\text { Interval } \\
\text { of The Difference }\end{array}$} \\
\hline & & & & & & & & & Lower & Upper \\
\hline \multirow{2}{*}{$\begin{array}{c}\text { Mean } \\
\text { STA- } \\
\text { PSV }\end{array}$} & $\begin{array}{c}\text { Equal } \\
\text { Variances } \\
\text { Assumed } \\
\end{array}$ & 62.586 & .000 & 18.837 & 94 & .000 & 21.291 & 1.130 & 19.047 & 23.535 \\
\hline & \begin{tabular}{|c|} 
Equal \\
Variances Not \\
Assumed \\
\end{tabular} & & & 18.837 & 52.841 & .000 & 21.291 & 1.130 & 19.024 & 23.558 \\
\hline \multirow{2}{*}{$\begin{array}{c}\text { Mean } \\
\text { STA-RI }\end{array}$} & \begin{tabular}{|c|} 
Equal \\
Variances \\
Assumed \\
\end{tabular} & 7.708 & .007 & 9.891 & 94 & .000 & 0.172 & 0.017 & 0.137 & 0.206 \\
\hline & \begin{tabular}{|c|} 
Equal \\
Variances Not \\
Assumed
\end{tabular} & & & 9.891 & 85.322 & .000 & 0.172 & 0.017 & 0.137 & 0.206 \\
\hline \multirow{2}{*}{$\begin{array}{l}\text { Mean } \\
\text { STA-PI }\end{array}$} & \begin{tabular}{|c|} 
Equal \\
Variances \\
Assumed \\
\end{tabular} & 22.900 & .000 & 24.047 & 94 & .000 & 0.895 & 0.037 & 0.821 & 0.969 \\
\hline & \begin{tabular}{|c|} 
Equal \\
Variances Not \\
Assumed
\end{tabular} & & & 24.047 & 72.004 & .000 & 0.895 & 0.037 & 0.821 & 0.969 \\
\hline
\end{tabular}

\section{Ultrasonography and Colour Doppler Images}
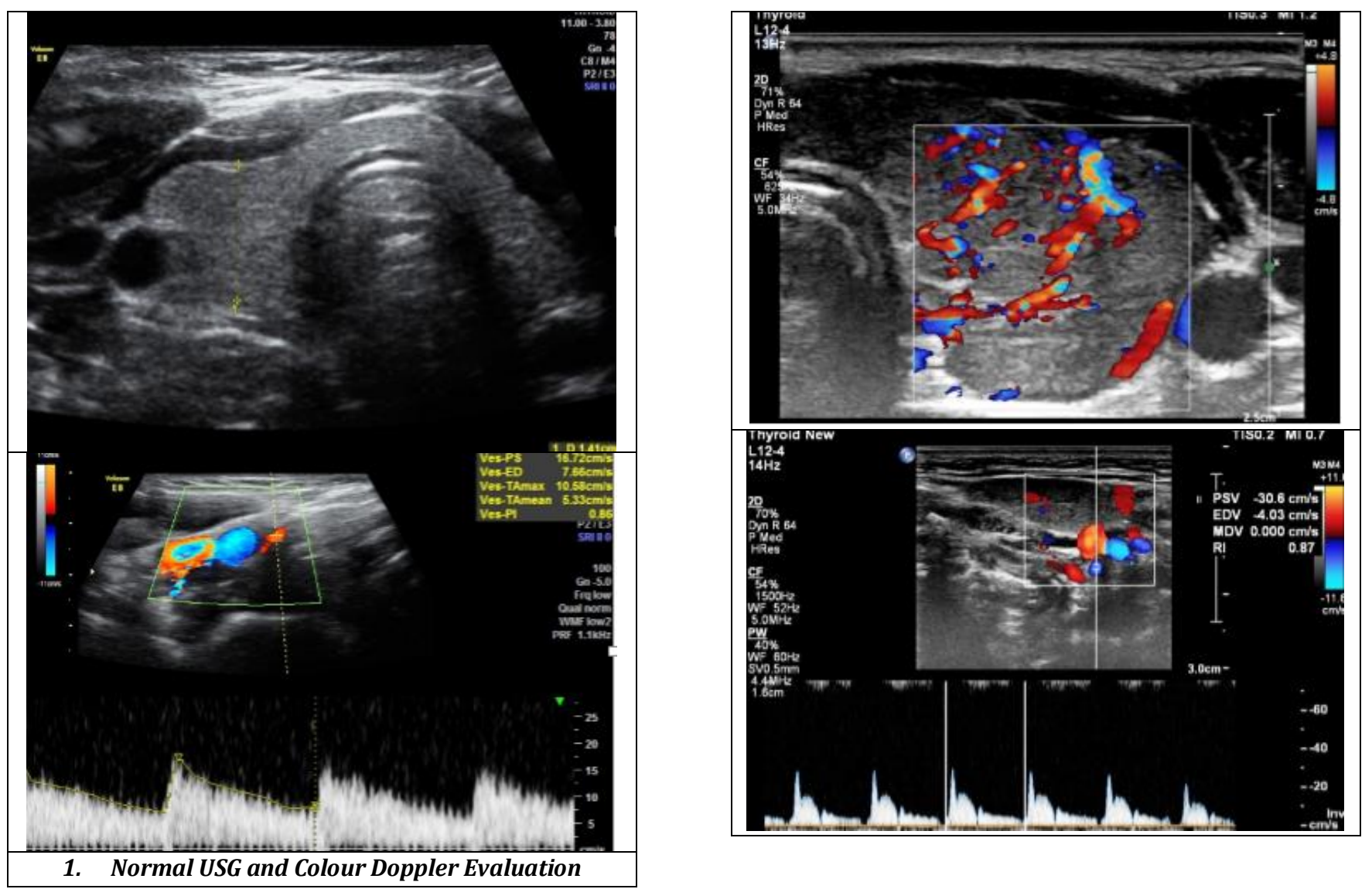


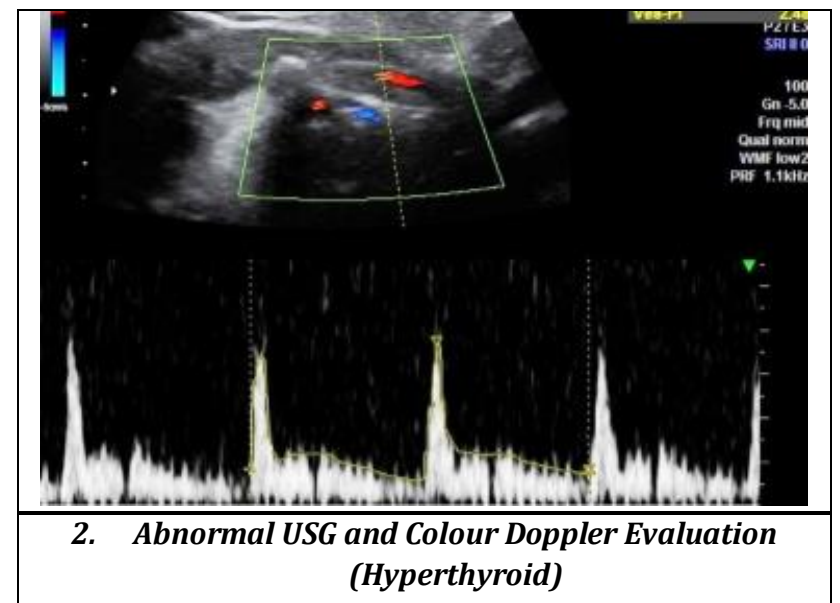

\section{DISCUSSION}

Hyperthyroidism is one of the most common diseases seen in the general population with middle aged females being most affected by it. It is diagnosed by a thyroid function test (TFT), which evaluates for the thyroid stimulation hormones, the triiodothyronine (T3) and the tetraiodothyronine (T4) levels. Additionally, and ultrasound scan of the neck is also done in most of the cases to assess the thyroid gland for any structural abnormality.

In our study we aimed to establish a relation between the TFT and the Doppler indices of bilateral superior thyroid artery, while using the ultrasonography reports to exclude patients with any exclusion criteria from the study.

The Doppler indices used were the peak systolic velocity, the resistive index and the Pulsatility Index.

We have found that a clear distinction exists between the Doppler indices of STA in euthyroid subjects and hyperthyroid patients, with significant increase in the Doppler indices in hyperthyroid patients.

Joish UK et al ${ }^{16}$ showed in his study that in clinically euthyroid patients the mean PSV-STA obtained was $16.94 \pm$ $5.3 \mathrm{~cm} / \mathrm{s}$. The mean PI-STA was $0.93 \pm 0.31$ and mean RI-STA was $0.55 \pm 0.13$. In our study we also got a similar result with the mean PSV-STA being $15.85 \pm 1.89 \mathrm{~cm} / \mathrm{s}$. The mean PI-STA was $0.9 \pm 0.12$ and mean RI-STA was $0.55 \pm 0.07$.

And in hyperthyroid patients, Sundarram KST et al ${ }^{17}$ studied the Doppler values in patients with graves' disease and other causes of hyperthyroidism and showed in their paper that the mean PSV-STA (cm/s) was $54.09 \pm 4.67$ and $28.92 \pm 4.39$, the bilateral mean RI-STA was $0.79 \pm 0.18$ and $0.67 \pm 0.12$; and the bilateral mean PI-STA was $1.95 \pm 0.33$ and $1.87 \pm 0.43$. In our study also we acquired comparable results in the Doppler indices of hyperthyroid patients; with mean PSV-STA $(\mathrm{cm} / \mathrm{s})$ being $37.15 \pm 7.6$, the bilateral mean RI-STA being $0.72 \pm 0.1$ and bilateral mean PI-STA being 1.79 \pm 0.23 , which may be due to not further subdividing hyperthyroid patients.

\section{CONCLUSIONS}

In our study which included 96 participants, with 48 cases and 48 controls, who were assessed with thyroid function tests, ultrasonography and colour doppler studies with doppler evaluation, we found that there was a significant correlation ( $p$-value $<0.05$ ) between the doppler indices and the euthyroid or hyperthyroid status of the subject.
It was in accordance with the studies reviewed in the review of literature for this study and the expected results were achieved. It may be suggested that the colour doppler evaluation with assessment of the doppler indices should be done in all patients who present with suspicion of hyperthyroidism and a TFT result which maybe subclinical or inconclusive. The doppler indices in such cases may be helpful in diagnosing and categorizing patients with otherwise questionable reports.

\section{REFERENCES}

[1] Rumack CM, Wilson S, Charboneau JW, et al. Diagnostic ultrasound: 2-Volume set. $4^{\text {th }}$ edn. Missouri: Elsevier Mosby 2010.

[2] Ruchała M, Szczepanek E. Thyroid ultrasound-a piece of cake? Endokrynologia Polska 2010;61(3):330-44.

[3] Bogazzi F, Bartalena L, Brogioni S, et al. Thyroid vascularity and blood flow are not dependent on serum thyroid hormone levels: studies in vivo by color flow Doppler sonography. European Journal of Endocrinology 1999;140(5):452-6.

[4] Zhao X, Chen L, Ling L, et al. Peak systolic velocity of superior thyroid artery for the differential diagnosis of thyrotoxicosis. PLoS One 2012;7(11):e50051.

[5] Huang SM, Chow NH, Lee HL, et al. The value of color flow Doppler ultrasonography of the superior thyroid artery in the surgical management of Graves' disease. Arch Surg 2003;138(2):146-51.

[6] Macedo TA, Chammas MC, Jorge PT, et al. Reference values for Doppler ultrasound parameters of the thyroid in a healthy iodine non-deficient population. Br J Radiol 2007;80(956):625-30.

[7] Ueda M, Inaba M, Kumeda $Y$, et al. The significance of thyroid blood flow at the inferior thyroid artery as a predictor for early Graves' disease relapse. Clin Endocrinol (Oxford) 2005;63(6):657-62.

[8] Erdoğan MF, Anil C, Cesur M, et al. Color flow Doppler sonography for the etiologic diagnosis of hyperthyroidism. Thyroid 2007;17(3):223-8.

[9] Narouze S. Beware of the "serpentine" inferior thyroid artery while performing stellate ganglion block. Anesthesia \& Analgesia 2009;109(1):289-90. 
[10] Toni R, Della Casa C, Castorina S, et al. A meta-analysis of superior thyroid artery variations in different human groups and their clinical implications. Annals of Anatomy-Anatomischer Anzeiger 2004;186(3):25562.

[11] Mary D. Thyroid gland in the endocrine system. Chap 15. Gray's Anatomy. 38th edn. Edinburgh London, New York, Philadelphia: Churchill Livingstone 1995: p. 1891-7.

[12] Werner SC. Classification of the eye changes of Graves' disease. Journal of Clinical Endocrinol Metab 1969;29:782-5.

[13] Jory NK, Robert JG. Disorders of thyroid gland. In: Cummins CW, Fredrickson JM, Harker LA, et al. eds. Otolaryngology Head and Neck Surgery. Mosby 1986;3:2499-507.
[14] Lucaya J, Berdon WE, Enriquez G, et al. Congenital pyriform sinus fistula. A cause of acute left sided suppurative thyroiditis and neck abscess in children. Pediatric Radiology 1990;21(1):27-9.

[15] IBM Corp. IBM SPSS statistics: Version 23.

[16] Joish UK, Kavitha Y, Reddy RH, et al. Doppler indices of superior thyroid artery in clinically euthyroid adults. The Indian Journal of Radiology \& Imaging 2018;28(1):10-3.

[17] Sundarram KST, Sadacharan D, Ravikumar K, et al. Role of Color Doppler ultrasonography in differentiation of Graves' disease from thyroiditis: a prospective study. World J Endoc Surg 2017;9(2):41-5. 